by compounding their own medicine? Seventhly. How is it that surgeons in the army and navy, not licentiates of the hall, are allowed to compound medicines, while in the service, although they cannot do so with impunity in the capacity of general practitioners? The same law holds good in the case of dispensary surgeons and physicians. Eighthly. How is it that neither the Society of Apothecaries nor the College of Surgeons can protect general practitioners from being deeply injured by the too frequent practice of prescribing over the counter by a set of ignorant druggists, a practice which, above all others, is most calculated to undermine the interests of the former class.

Here, then, is a series of the most monstrous abuses, not to be equalled in any other profession; and how are they to be remedied save by amalgamating the hall and college, together with suppressing the dangerous medical practice by druggists-tampering with the lives of so many thousands? How any government can for a moment sanction such a class of wholesale dealers in human life is to me extraordinary. Leaving the consideration of these all-important matters to Sir James Graham, to you, Sir, and other active medical reformers, I remain yours respectfully,

April 1, 1844.

A Surgeon.

\section{CLASS EXAMINATIONS IN EDINBURGH.}

To the Editor of THE LANCET.

SIR,-I beg through the medium of your valuable journal respectfully to sugrest to the professors of University College that the following rule, from the word " but" to the end, be at once repealed :-

"Frequent examinations are held in every class. Medals and certificates of honour are given in every class at the end of the term; but those pupils only who have regularly attended the examinations will be admitted to contend for them."

This was not adhered to last session, nor is it this; $I$ am, therefore, bound to conclude that the rule is a bad one, and consequently the sooner it is struck out the better. Were the rule, however, adhered to, a student would have au opportunity of judging, from the answers in the weekly examinations, of the proficiency of his opponents and of his own chance of success. He is now quite unable to do so, and of course cannot form an estimate of his own relative proficiency in any class. Much valuable time may thus be thrown away.

While, however, the rule exists, I consider that any student who has acted up to it is at perfect liberty to protest against a prize being awarded to another who has failed to do so. But this I will leave to those gentlemen who place a higher value on such rewards for merit than I do, and will content myself with calling the attention of the professors and students to the subjeet. If you could find room for this in next week's LA NCET you would much oblige, Sir, your obedient servant,

John Elxtotr Wood.

University College, March 23, 1844 .

\section{ANATOMICAL OVERCHARGES IN THE} UNIVERSITY OF EDINBURGH.

"Ob for a whip in every honest hand,

To lash the rascals naked through the world !"

\section{To the Editor of THE LANCET.}

SIR,-The fearless independence of principle evinced in the pages of THE LANCET, with its proverbial anxiety to forward the interests of medical students, and expose every imposition to which they may be subjected in the pursuit of their studies, induce me to call your attention and that of the medical faculty of this university to the following fact :-

The fee for the anatomical demonstrations and dissections in this university was, until the two last winter sessions, invariably rated at two guineas; now, at the before-mentioned period, the extra-academical teachers of anatomy, by a mutual agreement, raised their fees to four guineas; this they were, of course, at liberty to do, but the university demonstrator, with "genuine Yankee calculation," conceived that he also had the power of raising his fee, although, by so doing, he well knew that he was acting in direct violation of the university statutes. We have thus been compelled by this Shylock for the two last winter sessions to pay double the money charged in any of the preceding ones. But upon our talented professor of clinical surgery being this session appointed dean of the medical faculty, he directed his attention to this glaring imposition, and gave the worthy demonstrator to understand that the overplus should be returned to the oppressed students, which he, kind creature, at the time very faithfully promised should be done. Now comes the cream of the jest; from some cause or other, which I have been unable to fathom, the matter has been hushed up, and he has not yet in a single instance "opened his pouch "" on the contrary, this "just man" still continues unblushingly to receive his superfluous fees whenever they drop in, and this, too, in direct defiance of the dean's request to the contrary. As the season is now drawing to a close we feel anxious to have that which (in right) is ours refunded, and trust you will do us the justice to insert this letter in your Journal, so that such juggling chicanery may receive the exposure it so justly merits. Trusting that the gentle dose I have administered will act on the refunding part of his system. I subscribe myself, Sir, yours obliged,

Edinburgh, March 13, 1844.

\section{MEDICAL INFLUENCE IN THE ELECTION OF GUARDIANS.}

To the Editor of THE LANCET.

SIR,-Will you allow me, as a constant reader of THE LANCET, to make one or two observations on the letter of an " old General Practitioner." I am well aware that medical men long established in practice have great influence in the neighbourhoods in which they reside, but $\mathrm{I}$ am fearful it would not be sufficient to influence the election of proper guardians to the extent hinted at by an oldestablished practitioner. I know many guardians who are individually very liberal men, but take them as a body they are complete screxs, and will continue so as long as they have it in their power. If an old-established practitioner has not seen Mr. Guthrie's letter published in The LANCET and other medical journals, 23rd of December last, I would recommend him to refer to it. I am glad to find that Lord Ashley has succeeded in getting a committee to inquire into medical remuneration.

Medical men have been treated by the guardians much worse than butchers, bakers, or chandlers; they have worked for nothing, and given away their drugs, and now is the time to take the power out of the hands of these oppressors, not by electing proper guardians, but by stating. our grievances to the committee. I am, Sir, yours, \&c.

March 20, 1844. An Union Medical Man.

ON THE MEANING OF THE WORD AFFINITY.

To the Editor of THE LANCET.

Sir,-It is important that any defective illustration used by Professor Liebig to elucidate the true meaning of the leading terms recognised or used by him in his "Lectures on Organic Chemistry," should be made known, that no error, however otherwise unimportant, may arise in consequence. In the number of THE LANCET of the 30th ult., page 32, he says, "This chemical power has been styled affinity, in total defiance of the vernacular acceptation of the word." "This term (affinity) is decidedly wrong if it be intended to convey the meaning that such substances are related to each other." The term affinity in general use, as it is opposed to consanguinity, admits of but one definition, which is, that it is the tie arising from marriage betwixt the husband and the blood-relations of the wife; and betwixt the wife and the blood-relations of the husband. The word, therefore, appears to admit of the same construction in its common as it is in its chemical acceptation; parties connected by birth and consanguinity are related in their properties, 